\title{
Etnicidades, etno-territorios y conflictos mineros: aportes para una geografía humana de los aymaras en Chile $^{1}$
}

\author{
Hugo Romero-Toledo²
}

\begin{abstract}
RESUMEN
Este artículo analiza el fenómeno de la etnicidad aymara y la creación de etno-territorios en el marco de conflictos mineros y de la política indígena neoliberal. Las preguntas que guían la investigación son: ¿Cuál ha sido la evolución de las comunidades aymaras en el Norte de Chile?, ¿qué tipo de dinámicas se han establecido y en que territorios han ocurrido?, ¿cómo los conflictos mineros han fortalecido o perjudicado a las organizaciones aymaras? Para responder estas preguntas, primero se revisarán críticamente las perspectivas teóricas en torno a etnicidad y etno-territorios, para luego, identificar cómo las etnicidades y los etno-territorios, en cuanto construcciones sociales y proyectos políticos, van tomando forma, desde una perspectiva que combina el análisis de la literatura especializada, entrevistas, análisis estadísticos descriptivos de fuentes secundarias, y análisis espaciales.
\end{abstract}

Palabras claves: etnicidad, etno-territorios, territorio, aymaras, Norte Grande.

\begin{abstract}
This article analyzes the phenomenon of the Aymara ethnicity and the creation of ethno-territories in the context of mining conflicts and the indigenous neoliberal politic. The questions that guide this research are: How have the Aymara communities evolved in Northern Chile? What kind of dynamics has been established and in what territories have they been implemented? To answer these questions, the theoretical approaches about ethnicity and ethno-territory will be critically reviewed in the first place, and in the second place, there is an analysis about how ethnicities and ethno-territories take shape, as social construction and political projects, through a perspective that combines the analysis of the specialized literature, interviews, descriptive statistics analysis of secondary sources, and spatial analysis,
\end{abstract}

Keywords: etnicity, ethno-territorioes, Aymaras, Norte Grande.

\footnotetext{
La siguiente investigación ha sido financiada por el Proyecto FONDECYT de Iniciación № 11140265, por el Proyecto FONDECYT Regular № 1120204 y por el Centro de Estudios de Conflicto y Cohesión Social (COES), CONICYT/FONDAP No 15130009. El autor agradece a Felipe Castro por su apoyo en la elaboración de cartografía, a Nelson Martínez por sus valiosos aportes a este artículo, y en general, por las horas de discusión sobre geografía, y a Aurora Sambolín por la edición el documento final. Finalmente, agradece a su abuela, María Olivares, de quién recibió el gusto por el estudio, y que en el año 2017 falleció a sus 99 años. Artículo recibido el 30 de marzo de 2017, aceptado el 26 de junio de 2017 y corregido el 15 de septiembre 2017.
} 
En las regiones del Norte y Sur de Chile se han venido desarrollando tres grandes contradicciones territoriales. En primer lugar, el extractivismo de cuño neoliberal: minero en la zona árida del Desierto de Atacama, y el forestal, hidroeléctrico y salmonícola desde el Río Maule hacia el sur. En segundo lugar, una acelerada urbanización y la consolidación de ciertas ciudades vinculadas al ciclo de los commodities y especializadas en servicios, como lquique, Antofagasta, Temuco, Puerto Montt y Castro. Y, en tercer lugar, el surgimiento, organización y proceso de conflicto de una serie de identidades étnicas, entre ellas las de los aymaras en las regiones de Arica y Parinacota y Tarapacá, y los del mapuche, en las regiones del Bío Bío, La Araucanía, Los Ríos y Los Lagos. El siguiente artículo reúne una serie de elementos teóricos y empíricos que buscan entender, desde la geografía humana, la situación de los pueblos indígenas en Chile en general, y de las comunidades aymaras en el Norte Grande en particular, y el surgimiento de conflictos socioambientales asociados a la minería.

El proceso de organización de identidades étnicas indígenas ha sido registrado en la literatura como "el retorno de los indígenas" (Stavenhagen, 2002), la "emergencia indígena" (Bengoa et al., 2012), o el proceso de "surgimiento o construcción" étnica e indígena (Gundermann et al., 2014), esta literatura sugiere que dicha dinámica no implica solamente un simple resurgimiento, sino que además, y por sobre todo, se trataría de un proceso global de consolidación política de las luchas por un conjunto de derechos tales como; a la tierra y el reconocimiento del territorio, a una cultura propia, y a la autonomía, autodeterminación y representación política, que con la profundización del extractivismo y la urbanización ha generado conflictos etno-territoriales considerables en países postcoloniales, entre ellos Chile.

El siguiente artículo indaga sobre el fenómeno de la etnicidad aymara y la creación de etno-territorios en el marco de conflictos mineros y de la política indígena. Las preguntas que guían la investigación son ¿cuál ha sido la evolución de las comunidades aymaras en el Norte de Chile?, ¿qué tipo de dinámicas se han establecido y en qué territorios se han implementado?, ¿cómo los conflictos mineros han fortalecido o perjudicado a las organizaciones aymaras? Para responder estas preguntas, primero se revisarán las perspectivas teóricas en torno a etnicidad y etno-territorios, para luego, desde una perspectiva que combina el análisis de la literatura especializada, entrevistas, análisis estadísticos descriptivos de fuentes secundarias, y análisis espaciales, identificar cómo las etnicidades y los etno-territorios van tomando forma, en cuanto construcciones sociales y proyectos políticos.

\section{Etnicidad}

La etnicidad (del griego ethnos, que significa pueblo o nación) surge como concepto durante el siglo XX, para impugnar el concepto de raza, el cual, asociado al desarrollo de las ciencias naturales y la colonización, construyó un discurso sobre las diferencias fenotípicas de los seres humanos (entre ellos las medidas anatómicas y el color de la piel), y les atribuyó determinados atributos sociales y culturales, relacionados con supuestos estados de inteligencia y civilización (Wade, 2010). Por el contrario, el concepto de etnicidad ha apuntado a las diferencias culturales, enmarcado dentro de lo que en ciencias sociales es conocido como el "giro cultural" (Gundermann, 1997; Bello, 2004). La etnicidad es una forma específica de construcción de identidad de ciertos grupos emergida en el contexto de interacciones con el estado moderno y la economía 
capitalista, donde un grupo específico valora y defiende su identidad, al mismo tiempo, que participa/resiste de manera desigual, procesos de producción de subjetividad y legitimación por parte del estado y el mercado (Hale \& Millamán, 2006; Bello, 2016). Teóricamente, Max Weber (1978) definió "grupo étnico" como aquel basado en la creencia subjetiva de los miembros de un grupo de tener una común descendencia, en términos de percepción más que de rigurosidad histórica, comúnmente respaldado por similitudes físicas y culturales. Los orígenes de los estudios de etnicidad pueden ser trazados desde la escuela de sociología de Chicago, con trabajos como los de Park (1928) sobre los patrones de asentamiento y la conformación de los ghettos, donde la "etnicidad" estaba asociada a "minorías". El concepto cambió su acepción con los trabajos de Glazer \& Moynihan (1975), donde su significado se movió hacia grupos dominantes en la sociedad. Esto generó que en Europa el concepto de etnicidad sea cercano al concepto de nacionalidad, como referencia a un estado etno-cultural independiente de las fronteras del estado-nación. De esta forma, lo que en América es una minoría étnica, en Europa es una minoría nacional (Schaefer, 2008: 457).

Dentro de los debates más importante sobre el estudio de la etnicidad destacan los primordialistas y los instrumentalistas (Gundermann, 1997; Bello, 2004; Thorp \& Paredes, 2010). Por un lado, las posiciones primordialistas, como la de Geertz (1973), plantean que el grupo étnico está definido por diferencias culturales que se poseen, y por otro, las instrumentalistas, como la de Bates (1971), que sostienen que la situación individual y la identificación con un grupo étnico cambian de acuerdo con contextos y metas, y la identidad étnica se politiza en función, por ejemplo, de demandas de tierras, trabajos, acceso a mercados, entre otros. Dentro de este debate, el trabajo de Barth (1976) ha sido central para entender que las diferencias visibles y significativas entre los grupos no se basa en la "posesión" de ciertos atributos culturales, sino en la interacción social con otros grupos, que son las que definen "nosotros" y "ellos", y cuyas diferencias son marcadas mediante el establecimiento de "fronteras identitarias". A las anteriores posturas, habría que sumar una vertiente constructivista como la sugerida por Benedict Anderson (1983) sobre cómo comunidades culturales y políticas han tomado forma, y cómo sus significados han cambiado durante el tiempo, y el etnosimbolísmo del Anthony Smith (1991), quien introdujo una perspectiva sobre "colectividad cultural", destacando los atributos históricos y simbólicos culturales de identidad étnica, que, por un lado, tiene una memoria histórica esencial, y por otro, es producto de fuerzas históricas específicas, y está sujeta al cambio histórico (Smith, 1991: 20).

En la definición de Smith (2008), las comunidades étnicas o ethnies son formadas por procesos de etnogénesis, donde un sistema de códigos y símbolos, que tienen relación con categorías y redes étnicas, los efectos de la conquista y colonización sobre categorías culturales pre-existentes, y las actividades llevadas a cabo por elites religiosas e intelectuales, comienzan a ser compartidos, en procesos de carácter contradictorio internos al grupo y con influencias externas. En este sentido, existe una auto-definición o nombre propio, lengua, memoria histórica compartida, un territorio de origen o al cual están vinculados, ascendencia (por ejemplo, la construcción de mitos de ancestros comunes), prácticas religiosas, estética, y ciertos grados de solidaridad, que constituyen parte importante de las diferencias culturales asociadas a la identidad.

Aun cuando ciertos atributos culturales puedan aparecer naturalizados como propios de una identidad étnica, estos no son estables u homogéneos, sino que dinámicos y están en constante construcción. La etnicidad, por tanto, debe ser entendida dentro de un proceso de negociación, 
sobre lo que los grupos quieren enfatizar, en diferentes contextos y en diferentes escalas. Desde fines de la década de los noventa, se han venido desarrollando nuevas perspectivas, reconociendo a la identidad cultural y étnica como permanentes construcciones sociales, móviles y ambiguas, que surgen en contextos históricos y político-sociales específicos, dentro de un marco relacional y disputas de poder, recursos y posiciones dentro de una estructura social diferenciadora y desigual. Por tanto, las identidades no se definen por una serie de marcadores culturales, esenciales o ancestrales, que "fijan" a los sujetos, y desde donde emerge la legitimidad social y política de un grupo étnico específico. Por el contrario, las identidades son abiertas y heterogéneas, híbridas y en permanente cambio (Bello, 2004, 2016). Conceptos como "indigeneidad" en países como Perú (de la Cadena y Starn, 2009; García, 2005), Bolivia (Postero, 2013) y Honduras (Anderson, 2007), o el de "aboriginalidad" en Argentina (Briones, 1998) entre otros, han ido mostrando cómo la identidad indígena es producida política y culturalmente en múltiples escalas de interacción con lo "no indígena", a través de un proceso de construcción discursivo y simbólico, que tiene consecuencias prácticas en el mundo real.

\section{Etno-territorios}

La literatura europea de las ciencias sociales sobre etnicidades y territorios nos lleva directamente a temas de nacionalismo, conflictos étnicos y geopolítica. Mientras que en la literatura norteamericana sobre etnicidades y territorios se abordan, principalmente temas urbanos, de hibridez cultural y diáspora. En América Latina, la literatura aborda temas relativos a pueblos indígenas, territorios de origen, conflictos ambientales y territoriales, y "reemergencias" políticas. Dentro de estos tipos de estudio, existe la conceptualización de "etno-territorios", que hace referencias a aquellos territorios habitados por pueblos indígenas, delimitados por hitos geográficos reconocidos socialmente, que son valorizados porque poseen un contenido político, económico, social, cultural y religioso para una etnia u otra distinta (Molina, 1995). Los etno-territorios, en esta perspectiva, son los territorios culturales o simbólicos donde se establece la relación entre el proceso de identificación étnica y la práctica cultural (Barabas, 2002). Son territorios históricos, culturales e identitarios, habitados por grupos etnolingüísticos que lo reconocen como propio, y donde se producen y reproducen la economía y la cultura. Estos etno-territorios cumplen un rol fundamental para la construcción de identidades, dado que conecta a los pueblos indígenas con el hábitat de los ancestros y constituyen una herencia material y simbólica (Barabas, 2008).

En contraposición a la noción de territorio como un espacio geográfico dado, invariable o fijo atado a ciertos grupos étnicos, como lo sugieren los autores antes expuestos. En este artículo se lo problematiza como un proceso histórico de relaciones sociales. El territorio es una dialéctica que se asemeja a un palimpsesto (Hoskins, 1955), donde es posible apreciar diferentes tipos de construcciones estabilizadas y desestabilizadas en la historia, y donde lo sagrado o patrimonial existen, pero en confluencia y contradicción con relaciones de poder, funciones, dimensiones simbólicas y una multiplicidad de identidades de diferentes actores y en diferentes escalas, que están en conflicto por el control del espacio, y el manejo de mecanismos sociales (Paasi, 2003). En estas perspectivas, el poder social y político, la economía capitalista y la cultura occidental, toman forman y le dan forma al territorio, estableciendo sus límites y contenido, y las prácticas sociales, culturales, económicas y gubernamentales, que pueden llevarse a cabo en él. Es decir, 
en el territorio se articulan las relaciones sociales que necesariamente tienen una forma espacial, en la cual interactúan las unas con las otras, y donde coexisten una multiplicidad de diferentes trayectorias que siempre están en constante construcción, por lo cual el territorio nunca está totalmente hecho, cerrado o terminado (Massey, 2001, 2008).

Dado el uso crítico de conceptos como etnicidad e indigeneidad, lo que se plantea en este artículo es que los etno-territorios pueden ser entendidos como procesos sociales históricos, donde significados y prácticas culturales toman forma. Los etno-territorios surgen de la politización del territorio por ciertas identidades étnicas, que, por ejemplo, reivindican prácticas ecológico-culturales que cuestionan la forma en la cual el estado y las empresas especializan territorios y extraen recursos. La politización de estos territorios por parte de las identidades étnicas conlleva al despliegue de narrativas territoriales previas a la llegada de los geomensores estatales, creencias previas a la llegada de los misioneros, e idiomas y lenguas previas a la llegada de la escuela (Niezen, 2002). La construcción de etno-territorios hace referencia, por lo general, a espacios rurales que han sido el escenario de desposesión y donde la subsistencia en la tierra es una de las más importantes fuentes de autonomía y poder, aunque muchas veces esta construcción se desarrolla desde espacios urbanos (Perrault, 2012; Perrault \& Green, 2013). La politización étnica del territorio implica el desarrollo de prácticas de "ancestralización", mediante, por ejemplo, el establecimiento de límites sociales y geográfico físicos, que ayudan a fortalecer la territorialidad y la identidad, afianzando relaciones de parentesco y afinidad, y estableciendo protocolos sobre el uso de recursos naturales y de ciertos espacios comunitarios (Martínez, 2015). Desde estos etno-territorios, se cuestiona al extractivismo y al neoliberalismo multicultural, al mismo tiempo que se desarrolla una dialéctica de negociación/conflicto con formas de producción de subjetividades estatales y políticas de responsabilidad social empresarial.

Bryan (2012) sostiene que, el neoliberalismo en América Latina ha hecho que el estado acepte "perder" soberanía sobre ciertos territorios, a cambio de mantener el orden socio-espacial, por lo que le ha reconocido a pueblos indígenas y grupos afro-descendientes derechos colectivos sobre la tierra. De esta manera, formas dominantes de producción del territorio, como la gran minería o las empresas forestales de monocultivo, co-existen con formas subalternas de organización y control territorial, como las comunidades indígenas, tanto aquellas que están reconocidas en la ley, como aquellas en autonomía que están en conflictos contra el estado. Asimismo, el neoliberalismo multicultural compensa a los pueblos indígenas despojados de tierras y recursos en el pasado, con tierras, títulos de propiedad y capacitaciones laborales y culturales. Los estados y agencias internacionales designan territorios de etno-desarrollo, y ensayan políticas territoriales con pertinencia cultural (Radcliffe, 2010). De manera paralela, son los propios pueblos indígenas los que desarrollan un amplio repertorio de acciones colectivas territoriales y re-definen sitios de significación cultural, y negocian el uso y control de recursos. Es decir, "disputan el derecho de hacer sus propios lugares, más que a tener aquello hecho para ellos" (Castree, 2004: 136). En otras palabras, la constitución de etno-territorios representa la disputa territorial de los pueblos indígenas, no solamente sobre ciertos recursos o a ciertos lugares, sino que está conectada a luchas por reconocimiento, soberanías, y hacia la forma en las cuales se constituyeron los estados coloniales y el capitalismo (Coombes et al., 2012).

Precisamente, las tensiones socio-territoriales surgidas del aumento de la presión sobre ciertos medioambientes y poblaciones para la extracción de recursos, ha generado que ciertos gru- 
pos étnicos, por lo general marginalizados y minorizados, estén en un proceso de lucha por reconocimiento y autonomía territorial. Desde los setenta, diferentes organizaciones que tuvieron diversos orígenes, estrategias políticas, intereses políticos, identidades y preocupaciones territoriales, comenzaron a confluir para reclamar por las pérdidas, sufrimiento y las faltas a la honorabilidad, que ha significado la extracción de recursos y la modernización económica (Niezen, 2002). En décadas posteriores, como reacción a la conmemoración de los quinientos años del descubrimiento de América en 1992, se generó la denominada "emergencia indígena" (Bengoa et al., 2012), encabezada por movimientos indígenas que han basado sus demandas en el derecho a auto-representación y soberanía sobre sus territorios. En estos términos, tanto la identidad étnica como el territorio son construcciones sociales y proyectos políticos.

\section{Método}

La investigación ha seguido un enfoque multimétodo. Junto con establecer el estado del arte en cuanto a comunidades aymaras en el Norte de Chile, especialmente desde la antropología y en las revistas de la especialidad, se realizó trabajo de campo en la Región de Arica y Parinacota el año 2014, donde se visitaron la ciudad de Arica y los pueblos andinos Timar, Tignamar, Belén, Socoroma, Putre y Caquena. Durante los años 2014 y 2015, el trabajo de campo se centró en la Región de Tarapacá, donde se visitaron las ciudades de Iquique y Alto Hospicio y los pueblos de Quipisca, Mamiña, Macaya, Parca, Lirima, Cancosa, Collacagua, Pica y Huatacondo. Tanto en las zonas urbanas como en las rurales se realizaron entrevistas semiestructuradas de más o menos una hora de duración, las cuales han sido transcritas total o parcialmente. Las entrevistas contaron con consentimiento informado y el anonimato de los entrevistados se ha asegurado en todo momento.

También se ha trabajado con fuentes secundarias, principalmente con los informes de los proyectos mineros del Servicio de Evaluación Ambiental. Además, se realizaron análisis estadísticos descriptivos de la encuesta CASEN de 1996 a 2013, y de las bases de datos de CONADI para el pueblo aymara que incluyen comunidades y asociaciones, y miembros de comunidades. En el presente artículo solo se mostrará una parte de estos análisis.

Finalmente, se construyó cartografía en base a información proveniente de tres fuentes principales. En primer lugar, los asentamientos, centros urbanos y capitales regionales, fueron obtenidos de la base de datos cartográfica del precenso 2012. En segundo lugar, se utilizó la información de límites de las áreas de desarrollo indígena, información que se encuentra en la mapoteca online SITI de CONADI, específicamente la actualización del año 2016. En tercer lugar, para obtener las áreas de vegetación húmeda se utilizó la cobertura de uso de suelo de Chile del año 2014 del Laboratorio de Geomática y Ecología del Paisaje (GEP) de la Universidad de Chile. Dicha cobertura, a su vez, fue construida a partir de imágenes Landsat, por lo que el tamaño de pixel corresponde a 30 metros. Desde aquí se extrajeron los usos que representaban vegetación perteneciente a zonas húmedas, prescindiendo de la vegetación de tipo matorral. Las variables consideradas fueron: cultivos agrícolas, praderas, bosques, renovales, vegetación arborescente, entre otros tipos de vegetación asociada a cuerpos de agua. 


\section{El territorio de las comunidades aymaras}

Algunos autores señalan que el territorio aymara consiste hoy en "varios poblados andinos y estancias de comunidades aimara, constituidas por familias emparentadas y unidas a un territorio" (Molina, 2015: 30), con hitos geográficos como promontorios, cerros tutelares, quebradas, pastizales, humedales, vegas, ríos y vertientes, pero además las apachetas (montículos de piedras hechos por el hombre), y otros geosímbolos e iconografías que expresan relaciones y límites simbólicos y materiales. El paisaje esta socialmente demarcado y culturalmente connotado, en procesos que vinculan linajes y territorios, desde la época de los ayllus, y a las formas en que el Tawantinsuyu generó un sistema de demarcaciones y deslindes en las tierras, que luego fueron procesados como inscripciones, actas de conciliación territorial y títulos de dominios por parte de instituciones coloniales y republicanas, peruana primero, y chilena después. Esta secuencia muestra que el territorio no ha permanecido idéntico en el tiempo, en términos de sus formas de delimitación, de sus modalidades de apropiación y de la identidad colectiva de sus habitantes (González et al., 2014: 233). Es decir, revelan rasgos de lo que aquí denominamos como un palimpsesto, donde el territorio social y materialmente construido contiene trazos de construcciones sociales anteriores.

Dentro de las formas de producción del espacio andino precolombino, destacan los modelos socio-territoriales de complementariedad productiva de diferentes pisos ecológicos o archipiélago vertical (Murra, 1975), de valles o partes de valles costeros (Rostworowski, 1977), de movilidad giratoria (Núñez y Dillehay, 1979), y el modo altiplano (Browman, 1980), que hacen referencia a la circulación de relaciones sociales y productos a través de rutas y caravanas que unían a agrupaciones étnicas territoriales de las tierras altas con las tierras bajas. Estas formas socio-territoriales se vieron afectadas desde el siglo XVI, cuando los españoles impulsaron el agrupamiento o reducción de los ayllus a pueblos o markas, y la delimitación de tierra agrícola y de pastoreo. En algunos lugares se respetaron los linajes y los territorios, mientras que, en otros, se realizaron agrupamientos en nuevas tierras (Molina, 2015).

Los cambios radicales a la estructura agraria, tendientes a incrementar la minería, y el cambio en el sistema de tributos desde productos a dinero, generaron un sector empresarial hispano que producía ganadería, vid, aceite de oliva, entre otros, en las mejores tierras, y un sector de campesinos indígenas que persistía en sus espacios vitales recompuestos, en tierras marginales y de altura, a través de una producción de subsistencia (González et al., 2014). Es decir, la presencia española se concentró territorialmente en los valles bajos y la costa en el caso de Arica, y en los oasis y quebradas cercanas a la pampa en Tarapacá, mientras que la población indígena fue replegada a los territorios de la precordillera y al altiplano. Los indígenas siguieron habitando sus territorios históricos de estancias pastoriles y caseríos cercanos al ganado y a los cultivos, y generando negociaciones territoriales entre el ayllu y el pueblo reduccional, frente a la necesidad de intercambiar productos con zonas especializadas, y gestionar los conflictos por límites con españoles, caciques y comunidades. Este tipo de organización territorial es lo que se conoce como comunidades locales indígenas o comunidades reduccionales, las cuales quedaron compuestas por el uso familiar de la chacra y su relación con las tierras colectivas, por ejemplo, los terrenos de pastoreo, y espacios donde residían otros grupos familiares. Estas tierras estuvieron bajo un sistema de usufructo, donde las comunidades pagaban tributos y cumplían obligaciones al estado colonial (González y Gundermann, 2009). 
En el período republicano, las ideas liberales cuestionaron la categoría de "indio", construida durante la época colonial, y la reemplazaron por la de "ciudadano" (Gundermann, 2003). Esto significó la desestructuración de las comunidades indígenas para dar cabida a la pequeña propiedad y a las comunidades de particulares, lo que significó la perdida de control comunitario sobre recursos productivos y de autogobierno local (González et al., 2014). Este proceso ha sido registrado por una serie de autores a nivel mundial, entre ellos Vandergeest \& Peluso (1995) y Peluso \& Lund (2010), como un elemento central en la constitución de la tierra indígena en países postcoloniales. Con la anexión a Chile de estos territorios, el trámite de inscripción de propiedades indígenas comenzó a ser realizado en las ciudades puertos, lejanas a los territorios históricos indígenas. Se inició así la inscripción de títulos de propiedad aymara, lo que generó, en algunos casos, superposiciones de títulos entre diferentes individuos y grupos aymaras. En otros casos, la subdivisión de pueblos propició el surgimiento de nuevas comunidades aymaras (González y Gundermann, 2009).

La acción del estado moderno logró resultados disímiles en las tierras aymaras, en un esquema donde, por un lado, los títulos de propiedad individuales fueron aplicados a una población que no leía o escribía en español, y que en general careció de los medios para inscribir, actualizar y sanear derechos de propiedad. Por otro lado, dicha población tuvo agencia desde las propias normativas estatales, lo que comenzó a desarrollar una serie de conflictos entre los propios grupos aymaras. Por ejemplo, Castro (2016) ha presentado cómo los conflictos de tierra en los pastizales andinos se extendieron desde antes de la anexión a Chile, en el marco de las relaciones geopolíticas de Perú y Bolivia en el siglo XIX. Durante el siglo XX, el conflicto por tierras, generado por la acción u omisión del estado chileno, fue parte preponderante de la comunidad andina, así como también la propia agencia aymara, tanto como persistencia o como negociación, y tanto dentro de Chile como en la frontera con Perú y Bolivia. Por un lado, la creación de títulos de propiedad transformó a las comunidades históricas del período colonial, generando conflictos intra e inter comunitarios, pero por otro, fortaleció en términos materiales y simbólicos, ciertos poderes, posiciones y condiciones al interior de los grupos sucesoriales aymaras y de otros grupos locales (Molina, 2015; Vergara et al., 2013). Se produjo así una dialéctica territorial: por un lado, el estado chileno no logró desintegrar a la comunidad indígena mediante títulos individuales, y al mismo tiempo, la comunidad perdió cohesión interna y no logró recomponer la comunidad tradicional. Pero al mismo tiempo, dicha comunidad persistió en territorios históricos, aun cuando la situación de conflicto por tierra, y desde fines del siglo XX por agua, haya contribuido a la migración hacia otras zonas agrícolas, o las dinámicas de industrialización, urbanización y modernización, la haya empujado a trasladarse hacia centros urbanos.

La comunidad aymara empezó a ser entendida entonces como: “(...) un espacio de relaciones en que agentes sociales comunitarios (hogares, familias extensas, linajes, autoridades locales, etc.) desarrollan acciones y ocupan posiciones de poder" (Vergara et al., 2013: 230).

Según la literatura, las comunidades que emergieron en el período republicano son de dos tipos:

- Comunidades de valles agrícolas precordilleranos o comunidad local vallestera, cuya unidad de ocupación y propiedad es la chacra. Consiste en comunidades locales, nucleadas en pequeñas aldeas y circundada por áreas parcelarias (Gundermann, 2007), y organizadas para riego, actividades religiosas y representación frente al estado. 
- Comunidades ganaderas altoandinas, cuya unidad de ocupación y propiedad es la "estancia", que consiste en pastizales rústicos en vegas o bofedales, y se organiza en base a la herencia patrilineal de la tierra o régimen de propiedad sucesorial o "comunidad sucesorial". También cuentan con chacras y eras, que han sido subdivididas por herencia. La sociedad aymara altoandina está compuesta por una unidad doméstica, el grupo local con un linaje o sublinaje localizado (comunidad sucesorial) y la comunidad histórica (Vergara et al., 2013: 238).

Si bien, esta tipología de comunidades es bastante útil como marco de referencia, conviene señalar también que el proceso contemporáneo de reestructuración territorial y de las comunidades aymaras debe ser entendido como una co-construcción con el desarrollo de la industria minera del salitre a nivel global, especialmente en los territorios anexados por Chile a fines del siglo $X I X$. En efecto, las salitreras se transformaron en verdaderos enclaves, que demandaron enormes cantidades de recursos naturales, crearon un mercado laboral en la zona, imponiendo un estilo de vida urbano y ayudaron a proletarizar a la población andina (González, 2011). En este proceso, las comunidades indígenas contribuyeron a abastecer a las oficinas salitreras con productos y mano de obra (Van Kessel, 2003; Castro, 1997).

Con el fin del ciclo del salitre en el período entre las guerras mundiales, y la crisis social y económica que se desencadenó, la población aymara tuvo dos derroteros: una parte se replegó hacia sus territorios de origen en la precordillera y el altiplano, mientras que otros "bajaron" a las ciudades puertos como Arica, Iquique y Antofagasta. En palabras de dirigentes aymaras, la crisis del salitre comenzó a cambiar la dinámica territorial y demográfica de las comunidades:

"Pararon esas oficinas salitreras y los pueblos quedaron en el olvido, prácticamente llevamos más de sesenta años que no hay progreso para nuestros pueblos" (mujer aymara, tercera edad, noviembre 2014).

Como lo señalan diferentes autores, otras de las causas de la migración hacia zonas urbanas ha sido la educación de los hijos (Castro y Bahamondes, 1987; Grebe, 1998; Gundermann, 2003).

"Si. Nací allá, ahí me atendió una partera, me crie allá hasta como los quince años y después, por otras cosas, ya, hubo que venirse a la ciudad para, o sea, continuar el estudio" (mujer aymara, mediana edad, noviembre 2014).

“(...) con el tiempo ha evolucionado, nuestros hijos quieren estudiar, quieren ser profesionales, hay otra posibilidad de trabajo y eso es vida, pero jamás, nunca, a lo menos yo... mi comunidad, o sea, no vamos a dejar nuestra comunidad" (mujer aymara, tercera edad, noviembre 2014).

"Viví mi infancia, hasta como los seis años permanentemente, siempre... Y después, porque mis papás, mis hermanos mayores empezaron a entrar al colegio a lo que es la educación media, nos tuvimos que venir, porque en Mamiña solamente está el colegio hasta octavo básico" (mujer quechua, mediana edad, noviembre 2014).

Finalmente, la transformación minera de Chile de cobre, plata, litio, bórax y hierro (Gundermann y González, 2008), y el impacto de la minería sobre la disponibilidad y calidad del agua ha 
afectado, principalmente a las áreas de pastoreo de los territorios andinos y a la agricultura de los territorios precordilleranos (Van Kessel, 1985; Carrasco y Fernández, 2009).

"Por ejemplo Parca, que es el sector de la (Compañía Minera) Colorado, Pica que son temas que ya son verídicos, que a ellos ya les quitó el agua las minerías, Camiña estamos en vías de..." (hombre aymara, mediana edad, noviembre de 2014).

"(La Compañía Minera Doña Inés de) Collahuasi les quitó agua a Pica, a Matilla y Colorado al sector de Mamilla, Parca, Macaya" (hombre aymara, mediana edad, noviembre de 2014).

"También nos dimos cuenta, o sea, el destrozo que hace la minería, si bien es un adelanto, o sea, pero también hace un destrozo para nosotros irreparable referente a las aguas, referente a la contaminación" (mujer aymara, mediana edad, noviembre de 2014).

Producto de estos procesos ocurre lo que Gundermann y González (2008) han llamado "postcomunalidad", caracterizada por la desruralización, desagrarización, descampecinización y translocalización de la población aymara.

El extractivismo neoliberal ha impactado en la redistribución de la población andina en el espacio regional, que sin embargo mantiene una "continuidad transformada", basada en el parentesco consanguíneo o ritual, o en el origen desde la localidad rural, y en algunos casos, como señala Niezen (2002), en una memoria común sobre el despojo de sus territorios y medioambientes. De esta forma, en la sociedad aymara se articulan una serie de relaciones, redes, discursos etno-políticos y prácticas materiales y simbólicas, que conectan y tensionan lo rural y lo urbano, lo tradicional y lo moderno, y lo comunitario y lo individual.

Desde los cambios en el mundo rural y urbano emerge la comunidad translocalizada, definida por el hecho de que "las comunidades indígenas ya no pueden ser apreciadas como unidades sociológicas basadas en la copresencia" (Gundermann, 2003: 70). Estas comunidades no rompen el vínculo con las comunidades locales rurales y con la parentela, al mismo tiempo que desarrollan identidades étnicas y nuevas dinámicas andinas, a partir de organizaciones de base que reivindican estas identidades y nuevas estrategias político-económicas para los territorios. Estos procesos ocurren en medio de geopolíticas de tensión fronteriza, políticas multiculturales de corte neoliberal, especialmente aquellas derivadas de la Ley Indígena y la creación de la Corporación Nacional de Desarrollo Indígena (CONADI), y los conflictos surgidos por la expansión de la minería privada desde fines de la década los ochenta.

\section{Los etno-territorios aymaras en la actualidad}

Cómo se ha planteado en este artículo, la identidad y el territorio no son cosas que un grupo determinado simplemente posea, sino que son procesos sociales e históricos que, a partir de diferentes tipos de contradicciones y conflictos entre diferentes actores, se van estabilizando y desestabilizando de manera provisoria. En la siguiente sección se ilustra cómo se van co-construyendo las etnicidades y territorios aymaras en el Norte Grande de Chile, desde la postcomunalidad. 


\section{Los cambios y dinámicas rurales y urbanos}

Las transformaciones territoriales de la segunda mitad del siglo XX han ido dando forma a una serie de procesos de reciente eclosión. En lo rural, comenzaron a darse dos procesos etno-territoriales de importancia: 1) la creación de las juntas de vecinos, y 2) la municipalización del espacio precordillerano y andino. En Chile, en general, se han creado municipios sin pertenencia cultural o étnica en términos espaciales, sino netamente funcionales. Por ejemplo, los municipios andinos pese a tener grandes extensiones territoriales son ocupados por una escaza población. Estas formas de organización socio-espacial surgieron en un contexto de descentralización de las funciones del estado, y al mismo tiempo, de conflictos geopolíticos en la triple frontera, especialmente desde el período de la dictadura militar. La población que habita en estos municipios se relaciona o se auto-identifica como aymara, y dada la consolidación de la propiedad de la tierra de carácter individual, está concentrada en, o en las cercanías, del antiguo poblado o reducción colonial. La junta de vecinos se transformó en el aparato mediante el cual los habitantes aymaras se han relacionado con las municipalidades, estableciendo en muchos casos, relaciones clientelares, las cual deben ser entendidas dentro de la complejidad del poder en los territorios cordilleranos y fronterizos. Por lo general, dentro de la gestión municipal, las autoridades indígenas en general, y aymara en particular, no han tenido cabida, como tampoco el derecho consuetudinario o las normas tradicionales (Gundermann, 2007), más allá de la que establece la multiculturalidad neoliberal y la folklorización de los pueblos indígenas. Aun así, alcaldes y concejales aymaras han sido elegidos.

Estas elites políticas aymaras, como señalan Aranda y Gely (2016), han ido reconfigurando la representación material y simbólica del espacio aymara que se superpone al mapa del estado, y que resalta un habitar transfronterizo, que permite el abastecimiento de bienes y servicios a ambos lados de los Andes. De esta manera, los territorios aymaras municipalizados se articulan con prácticas "paradiplomáticas", a partir de organizaciones como "Aymaras Sin Fronteras" que se constituyó en 2001, y que reconocen las etnicidades compartidas entre Perú, Bolivia y Chile, en el marco de un discurso identitario regional andino. Así, se subvierten las tensiones geopolíticas de la triple frontera, amparados en una práctica material y discursiva de un territorio común aymara, a través de la promoción de relaciones entre gobiernos locales municipales, con ediles aymaras, o alcaldes de comunas con alta población aymara en Chile, quienes establecen relaciones con unidades análogas fuera del país.

Por su parte, en el espacio urbano, los aymaras que se desplazaron hacia las ciudades puerto también generan estrategias identitarias y territoriales y comienzan a protagonizar un revival étnico-cultural (Carrasco y González, 2014: 220), con una fuerte identidad vinculada a las localidades rurales de origen, y a través de la creación de una serie de asociaciones y organizaciones económicas, locales y culturales. Esto les ha permitido la inserción en la ciudad, y al mismo tiempo, procurar la continuidad y reproducción socio-simbólica en espacios urbanos, y la representación y legitimidad frente al estado, para llegar a constituir una ciudadanía diferenciada (Chamorro, 2013; Gavilán, 2015), que busca mayor inclusión social (Gavilán y Lagos, 2014).

El análisis estadístico descriptivo de los datos de CASEN desde 1996 muestran un aumento sostenido en las personas que se auto-identifican como aymaras. En CASEN 2013 (el año de mayores números de auto-identificación), los aymaras fueron el pueblo indígena más importante del 
Norte de Chile: ellos representaron el 29\% de la población de la Región de Arica y Parinacota, el $13 \%$ de la Región de Tarapacá, y el 1,5\% de la población en la Región de Antofagasta. El grueso de la población que se auto-identifica como aymara reside en zonas urbanas, especialmente en las ciudades puertos y en el semiurbano de Arica, Iquique y Alto Hospicio. En las unidades urbanas menores como Putre, Pozo Almonte, La Tirana y Pica se encuentran aymaras que practican la agricultura, por ejemplo, a través de derechos de agua inscritos a nombre de asociaciones indígenas. El análisis de la serie histórica de CASEN, desde 1996 a 2013 (Figura N 1), muestra un aumento sostenido de la auto-identificación con el pueblo aymara en el Norte Grande, la cual pasó de 33.738 personas ( $67 \%$ urbano y $33 \%$ rural) a 91.835 ( $83 \%$ urbano y $17 \%$ rural) en este período de tiempo. En la Región de Arica y Parinacota, la población aymara alcanzó 47.627 personas (81\% urbano), mientras que en la Región de Tarapacá la cifra se elevó a 37.307 (84\% urbano). En la Región de Tarapacá, se registró un aumento de 12.197 personas que se auto-identificaron como aymaras entre el año 2009 y 2011. Es decir, el análisis de los aymaras ha salido de las lecturas del espacio comunitario, y se ha ampliado hacia las formas urbanas de la etnicidad (Aravena, 2014), y a la capacidad de producir territorios más allá de los espacios tradicionales, como lo hace Chamorro (2013) con el carnaval andino urbano, o la co-producción de territorios por diferentes actores, entre ellos las comunidades translocalizadas y la población aymara auto-identifica no comunitaria, pero también por parte del estado, y las compañías mineras (Romero-Toledo y Gutiérrez, 2016).

Figura $\mathrm{N}^{\circ} 1$

Dinámica de auto-identificación aymara en el Norte Grande

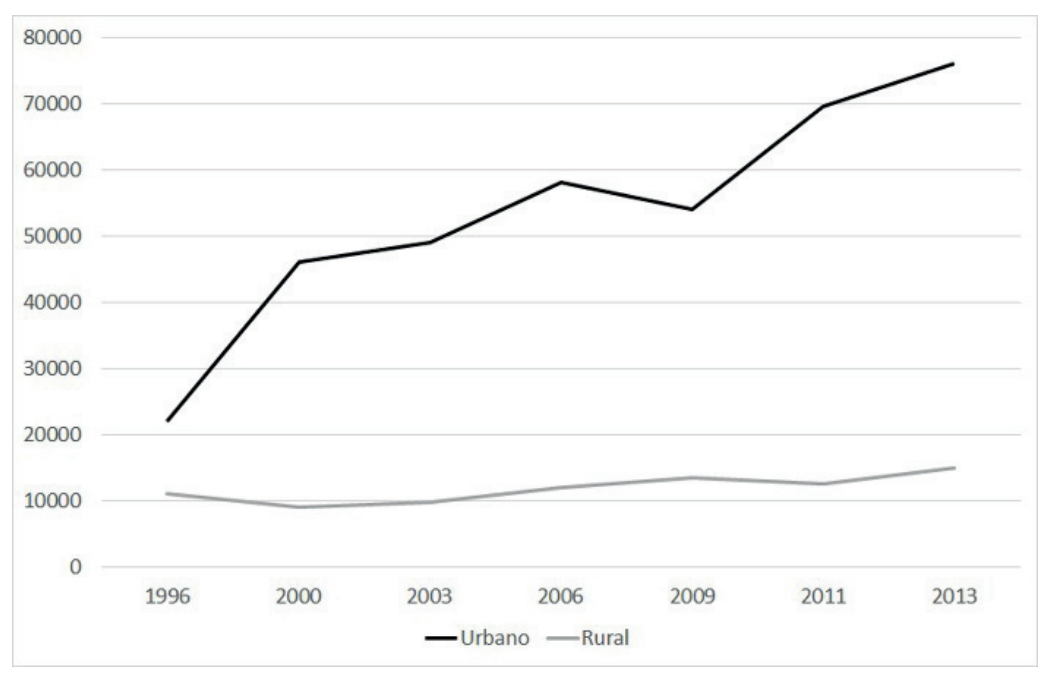

Fuente: Elaboración propia sobre la base de CASEN desde 1996 a 2013

\section{Las comunidades aymaras de la política indígena}

A los cambios registrados en el territorio, producto de la migración desde los espacios rurales andinos tradicionales, y la conformación de identidades y territorialidades aymaras urbanas, hay que sumar los procesos desencadenados por las tecnologías de la política indígena neoliberal. En ella, confluyen la creación de comunidades funcionales, la certificación de la calidad de indígena, 
la creación de Áreas de Desarrollo Indígena, y la emergencia de dinámicas de negociación/conflicto con las agendas políticas de dirigentes aymaras y sus bases, y la realidad de la comunidad aymara cordillerana con la comunidad translocalizada. En este proceso, ha sido central la producción de una memoria aymara, desarrollada por una elite aymara desde espacios urbanos, para la construcción de una identidad étnica fuertemente asociada afectivamente al espacio rural andino (Zapata, 2007), estrategias que contribuyen a consolidar la idea de un pueblo y territorio aymara.

Es así como a partir de la Ley Indígena de 1993, se reconoció como indígenas a aquellos que descienden de los ocupantes del territorio nacional de Chile, desde la época precolombina y que conservan manifestaciones étnicas y culturales, "siendo para ellos la tierra el fundamento principal de su existencia y cultura" (Ley 19.253, Artículo 1). La Ley Indígena reconoció como indígenas a los chilenos que son hijos de indígenas, es decir, que desciendan de los pueblos originarios cuyas tierras de origen sean los títulos entregados por el estado, o las tierras que históricamente han ocupado y poseen personas o comunidades indígenas. Además, fueron considerados como indígenas aquellos de apellido indígena y que lo acrediten por generaciones, y aquellos que, no descendiendo de indígenas, tienen prácticas y formas de vida indígenas (Ley 19.253, Artículo 2).

A partir de dicha ley, y la creación de la CONADI, se abrió un nuevo escenario de etnicidades y territorialidades a nivel nacional. La ley introdujo referencias específicas al territorio y su carácter comunitario en las comunidades indígenas aymaras (además de likan antai y quechuas en el Norte Grande), especialmente en los recursos naturales y específicamente con el agua. A través de esta ley emergió un nuevo tipo de comunidad con personalidad jurídica, autoridades electas, y sistemas de gestión que han tenido un funcionamiento dispar, pero que han contribuido a que los territorios andinos de precordillera y altiplano vuelvan a vibrar.

"Son cerca de diez organizaciones acá, más la junta de vecinos. Miembros indígenas y no indígenas, pero casi la mayoría son indígenas. Se habla de las distintas organizaciones que hay, las cuales son todas quechua y aymara. Algunas están activas y otras no. Frente a la CONADI hay que renovar cada cierta cantidad de años la directiva e ir enviando actas para que sepan que la organización está funcionando" (mujer aymara, mediana edad, mayo de 2015).

"Entonces a raíz de todo eso yo dije, bueno, me voy a hacer visible porque quiero que las platas realmente lleguen a mi pueblo y no se pierdan en el camino, entonces allí asumí la directiva, para ser primero tesorera de la comunidad indígena, después fui secretaria, y ya llevo tres periodos como presidenta, he sido re elegida y re elegida" (mujer aymara, mediana edad, mayo de 2015).

Según el catastro de CONADI 2017, en la Región de Arica y Parinacota existen setenta y cuatro comunidades aymaras, y dos quechuas, y en la Región de Tarapacá, ciento seis comunidades aymaras y seis quechuas. Es decir, desde la política indígena se han inscritos ciento setenta comunidades aymaras. A partir de la base de comunidades y sus miembros inscritos en CONADI de 2017 hemos calculado que, en total, 6.807 aymaras pertenecen a comunidades (cerca del 7\% de la población total de aymaras de las dos regiones extremas del Norte). En estas comunidades confluye la parte de la población que reside en el poblado andino y los caseríos, y la que emigró a espacios urbanos, tanto en los oasis y valles, como a las ciudades puertos. Como organizaciones sociales 
y políticas modernas, son afectadas por una serie de dificultades, como procesos eleccionarios, relaciones con otras comunidades, y negociaciones con empresas y con el estado. Por ejemplo, estas comunidades son centrales en la "Consulta Indígena" para la construcción e instalación de proyectos de inversión, pero también para las negociaciones directas de los mecanismos de compensación y mitigación de dichos proyectos, o de otros ya instalados, como es el caso de las mineras cupríferas de la Región de Tarapacá.

De manera paralela al aumento de la auto-identificación urbana, y la creación de las comunidades con personalidad jurídica, se crearon, a través de CONADI, las Áreas de Desarrollo Indígena (ADI) (Figura $N^{\circ} 2$ ), donde es posible identificar la producción de etno-territorialidad por parte del estado. Una ADI, según la ley, es entendida como una unidad territorial, donde se focalizan recursos para las comunidades indígenas. Los criterios para la designación de un ADI se basan en la ocupación ancestral del territorio, alta densidad de población indígena, homogeneidad ecológica y dependencia de recursos naturales como la tierra, el agua, flora y fauna. Según los documentos oficiales, las ADIs tienen como objetivo la superación de la pobreza, el rescate de la cultura y acoger las demandas de tierras, aguas y organización. En el Norte Grande se han constituido las siguientes ADIs aymaras Alto Andino en la Región de Arica y Parinacota (2004), y Jiwasa Oraje (2001) en la Región de Tarapacá. Con la conformación de las ADls se forma una nueva geografía aymara: por una parte, se han inscrito comunidades y asociaciones indígenas que conectan el territorio originario del altiplano y la precordillera con la población indígena que vive en zonas

Figura $\mathrm{N}^{\circ} 2$

Asentamientos, áreas vegetacionales y proyectos mineros en las regiones de Arica y Parinacota y Tarapacá
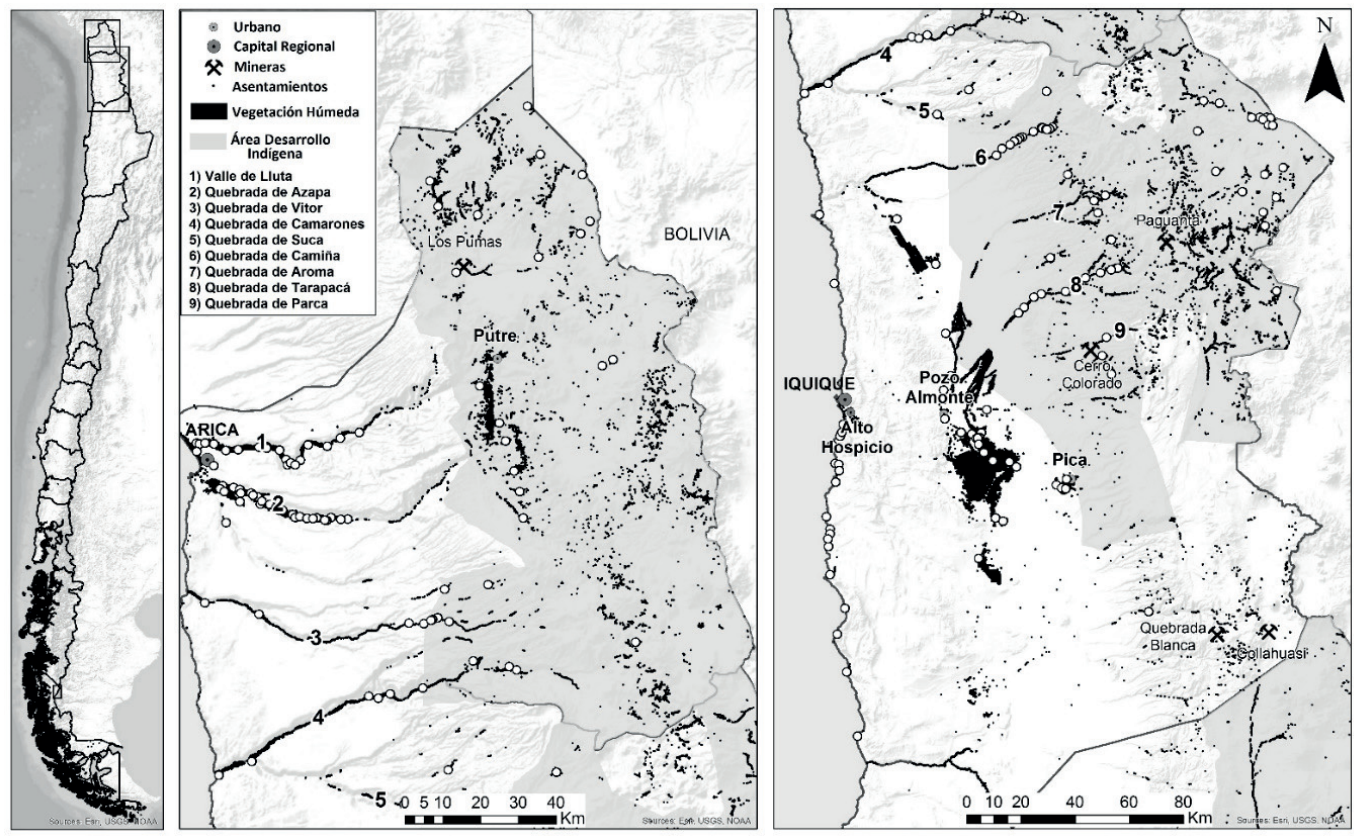

Fuente: Elaboración propia. 
urbanas. Por otra parte, se reconoce a las comunidades como organizaciones que tienen presencia territorial, y que demandan el control de la tierra y el agua, fuertemente presionada por el crecimiento urbano y el boom minero.

La Figura $N^{\circ} 2$ ilustra este proceso: los viejos poblados andinos, afectados por la migración desde mediados del siglo XX, se mantienen metabólicamente unidos a la reproducción de la población aymara urbana. Las comunidades aymaras de CONADI co-construyen esta relación, al transformarse en organizaciones políticas que median con el estado y las empresas, para asegurar el futuro de sus miembros. La presencia aymara en la precordillera y altiplano se fortalece asociada a reivindicaciones étnicas y territoriales, a la promoción de proyectos productivos, la compra de tierras y derechos de agua por parte de CONADI, y las medidas de compensación y mitigación de las mineras en los poblados cercanos. Como se aprecia en la figura $N^{\circ} 2$, el poblado colonial base de la comunidad tradicional persiste en aquellos lugares donde es posible identificar áreas vegetacionales. Esto señalaría, como lo hemos visto en terreno, el mantenimiento de prácticas ecológico-culturales de subsistencia para una población reducida que mantiene sistemas tradicionales de producción. En medio de esto, se instalan como capas, las ADIs, como una forma de planificar la inversión territorial y "los principios de etnodesarrollo y/o desarrollo con identidad. En síntesis, el Área de Desarrollo Indígena Jiwasa Orjae, supone un plan de trabajo que instaura una nueva etapa y un nuevo estilo de inversión para generar un desarrollo con identidad para las comunidades indígenas que integran el ADI" (CONADI, 2011: 4). En medio de los ADIs, es posible identificar el emplazamiento de los proyectos mineros Los Pumas, Paguanta y Cerro Colorado, y entre los ADIs Jiwasa Oraja y el Alto Loa, los yacimientos Quebrada Blanca y Collahuasi.

\section{Los etno-territorios aymaras y los conflictos mineros}

En Chile, un nuevo ciclo de extractivismo minero comenzó a ser desarrollado a través de las políticas neoliberales y las reformas profundas a las inversiones extranjeras (1974) a la tierra (1979), al agua (1981) y la minería (1983). En la década de los noventa comenzó en la Región de Tarapacá la explotación de los yacimientos Quebrada Blanca, Cerro Colorado y la Compañía Doña Inés de Collahuasi. La transformación minera posibilitó que las mineras ejercieran una enorme presión sobre los recursos hídricos localizados en territorios donde viven comunidades aymaras, quechuas y atacameñas (Molina, 2012; Prieto, 2016; Salinas, 2012; Yáñez y Molina, 2011, 2008). En este contexto, la Ley Indígena de 1993 incorporó referencias específicas para la protección del territorio y el agua de las poblaciones indígenas del Desierto de Atacama, reconociendo derechos y usos comunitarios del recurso hídrico.

En el corazón del ADI Jiwasa Oraje se emplaza el yacimiento minero de cobre Cerro Colorado. En las inmediaciones de la obra se encuentran los poblados precordilleranos de Parca, Mamiña y Quipisca. Además, en esta zona se está desarrollando el proceso de organización de los quechuas, específicamente en Mamiña, Macaya y Quipisca. Precisamente en esta zona hemos registrado una dinámica de negociación/resistencia que nos parece central al momento de analizar la articulación etno-territorial aymara: las empresas mineras generan impacto ambiental de importancia, tanto por la captura de agua, como por el polvo en suspensión que contamina las tierras y las aguas, y que causan alteraciones significativas a la vida de los poblados. Pero al mismo tiempo, las mineras despliegan sus políticas de responsabilidad social (Amilhat Szary, 2013). por el espacio andino, fortaleciendo los servicios básicos, servicios de salud y telecomunicación 
en los pueblos. Es decir, las comunidades se afectan y se fortalecen de manera dialéctica, y el resultado ha sido que el territorio precordillerano y de altiplano vibra con estas contradicciones.

Uno de los casos más representativo de conflicto entre compañías mineras y comunidades aymaras es el conflicto entre la Compañía Minera Cerro Colorado (CMCC) y la comunidad aymara de Cancosa, localizada en el altiplano de la Región de Tarapacá, por la afectación del humedal de Lagunillas, desde donde la CMCC extrae el agua para sus procesos industriales (Salinas, 2012; Yáñez \& Molina, 2011; Larraín \& Poo, 2010; Mamani, 2008). Este episodio conllevó una institucionalización de la relación entre la comunidad y la empresa, y les permitió a las comunidades de la precordillera, cercanas a la operación de la CMCC, articularse bajo nuevos formatos organizativos, derivados de la Ley Indígena, como comunidades y asociaciones indígenas. Esto generó un proceso de transformación política por la defensa de los recursos naturales y su patrimonio ancestral, y la búsqueda de compensaciones y mitigaciones por los impactos y alteraciones que genera la actividad minera en los territorios donde ellos viven o desde donde provienen. Según una reciente publicación en la prensa, el acuerdo consistió en US\$350 mil anuales para financiamiento de programas de desarrollo, US\$150 mil para becas, y US\$ 105 mil para un plan de cooperación. El acuerdo, además, incluía US\$ 575 mil para implementar los apoyos económicos, fondos que en total sumaban más de US\$11 millones hasta el 2030 (Rojas, 2017).

De esta forma, en el marco del conflicto minero se comenzó a dar un proceso de auto-reconocimiento aymara, y posteriormente quechua, donde confluyó la parte de la comunidad que persistía en el altiplano y la precordillera, con la parte de la comunidad que había migrado a las ciudades (Romero-Toledo y Gutiérrez, 2016). Las comunidades aymaras de Cancosa y Lirima en el altiplano, y Parca, Mamiña, Macaya y Quipisca (estas tres en proceso de organización como quechuas), en la precordillera y quebradas, son las que reclaman por considerarse directamente afectadas por la operación de la cuprífera Cerro Colorado: Cancosa y Lirima por extracción de agua, Mamiña, Parca, Macaya y Quipisca por encontrarse aguas abajo de la zona de extracción, por el polvo en suspensión y su impacto sobre el agua, la tierra, y los seres vivos, por el transporte de minerales y residuos, y en el caso de Mamiña, por haber sido especializado como campamento minero. En todos estos poblados la CMCC ha implementado una serie de medidas de mitigación y compensación, que constituyen parte de la producción del territorio minero, entre ellos: construcción de edificios de sedes comunitarias, mejoras de servicios de salud, arreglo de iglesias, mejoras de conectividad celular e internet, paneles solares, sistema de proyectos concursables, becas de estudios, entre otros.

Junto a este conflicto emergió, a mediados de la década del dos mil, un incipiente conflicto entre, por un lado, las comunidades aymaras que reivindican el Salar del Huasco (en esa época un humedal declarado sitio Ramsar), y, por otro, la minera Doña Inés de Collahuasi por la posible extracción de agua y la afectación del oasis de Pica y Matilla. La minera Doña Inés de Collahuasi ha sido acusada por las comunidades y activistas de haber extraído agua sin los estudios hidrológicos adecuados, lo que habría afectado los salares de Michincha y Coposa (Yáñez y Molina, 2008). El 2010, el Salar del Huasco fue declarado Parque Nacional, y el 2015 fue desafectado, ya que se acogió un recurso de invalidación presentado por tres familias de la zona pertenecientes a la Asociación Indígena Aymara Laguna del Huasco, basados en que no se había realizado el proceso de consulta indígena. Finalmente, la extracción de agua desde el salar no prosperó. 
El conflicto abierto entre comunidades aymaras y empresas mineras durante los últimos años se ha generado principalmente con las mineras no cupríferas. El primero de ellos en la cuenca del Lluta, la de mayor presencia de aymaras rurales en Chile, en contra del proyecto de manganeso Los Pumas. El proyecto se localizaría al noroeste del Complejo Volcánico Tarapacá, a un kilómetro del Parque Nacional Lauca, y en medio del ADI Alto Andino. El informe del Servicio de Evaluación Ambiental señala que el impacto de Los Pumas en el medio humano se concentraría en sitios arqueológicos, y en las comunidades aymaras de la localidad de Putre y sus alrededores, por el impacto demográfico que el proyecto podría generar. En términos medioambientales, los impactos se concentrarían en la extracción de agua y sobre flora y fauna protegida. La Coordinadora Aymara de Defensa de los Recursos Naturales de Arica y Parinacota (CADRN) fundada en 1999, organizó la defensa del Parque Nacional Lauca, y se opuso desde un primer momento al proyecto Los Pumas (Rodríguez, 2016). El agua, principalmente la del río Lluta, pero también la subterránea, se transformó en el elemento clave de politización, y su posible captura, sobreutilización y contaminación, con las consecuencias que esto traería para la cosmovisión aymara, se transformó en uno de los argumentos más fuertes. Esto permitió la invocación del Convenio No 169 de la OIT y la Declaración de las Naciones Unidas sobre Pueblos Indígenas. Finalmente, en el año 2015, tras una serie de acciones legales a nivel regional y nacional, y la masificación de las protestas a escala regional, donde la demanda ambiental funciona como un paraguas de otras demandas, el Comité de Ministros de Estado (medioambiente, salud, energía y minería) revocó el permiso ambiental del Proyecto Los Pumas, sustentado en la falta de estudios hidrológicos, sísmicos y el incumplimiento del Convenio No 169 de la OIT (Resolución Exenta N¹30/2015).

El segundo conflicto con minería no cuprífera es el que se desarrolla en la quebrada de Tarapacá contra la minera Paguanta. En noviembre de 2014, los Pueblos Indígenas Unidos de la Cuenca de Tarapacá, Quebrada de Aroma, Coscaya y Miñi-Miñi ingresaron al Tribunal Ambiental una reclamación contra la decisión del Comité de Ministros que aprobó el Estudio de Impacto Ambiental (EIA) de dicho proyecto minero. Paguanta, ubicada en la comuna de Huara, en la Región de Tarapacá, y en el ADI Jiwasa Oraje, consiste en una serie de prospecciones en búsqueda de zinc, plata y plomo, por US $\$ 50$ MM. Las observaciones presentadas por las comunidades aymaras en 2013, en el marco del proceso de participación ciudadana de la Evaluación de Impacto Ambiental, señalaron que el área de influencia era el territorio que corresponde a los "Pueblos Indígenas Unidos de la Cuenca de Tarapacá", sumando a todos los aymaras que viven en los sectores rurales, y en la gran zona urbana de Iquique y Alto Hospicio. Esto permitió construir el argumento de que como territorio se habría vulnerado su derecho a consulta consignado por el Convenio $N^{\circ} 169$ de la OIT, y que existe una relación material y espiritual con el territorio y sus recursos, especialmente con el "recurso hídrico, que es la base de nuestras culturas" (Observaciones Paguanta, 2013: 2). Además, las operaciones de Paguanta ya habrían dañado sitios arqueológicos que constituyen el patrimonio cultural de las actuales comunidades aymaras. El conflicto permitió la (re)apropiación de los aymaras contemporáneos de su geografía sagrada y su ecología cultural. Por ejemplo, la identificación de cerros tutelares o Malkus y T'allas, las apachetas, la valorización de las fiestas, prácticas y rituales, como la limpia de canales, qulla de las chacras, entre otros (Observaciones Paguanta, 2013). Es decir, este conflicto les permitió a las comunidades aymaras de la Quebrada de Tarapacá presentar un territorio vibrante y central para su resignificación identitaria. Sin embargo, el Tribunal Ambiental concluyó que las observaciones de los pueblos indígenas de Tarapacá sí fueron consideradas en la evaluación y que, siendo un proyecto de exploración de reducido alcance, sólo afectaría a la comunidad de Cultane y no a 
las comunidades reclamantes. Actualmente, los inversionistas abandonaron el proyecto, y tienen cinco años para ejecutar las obras de acuerdo a la resolución de calificación ambiental, de lo contrario debe volver a ser presentado.

Los conflictos Cerro Colorado, Salar del Huasco, Los Pumas y Paguanta muestran la contradicción territorial entre la localización de la inversión minera, central para el crecimiento económico del país, y la fuerza que han ido desarrollando las comunidades aymaras translocadas, reconocidas en cuanto a su existencia y ocupación territorial, que procesan lo ancestral y actual, y avanzan en términos políticos. Desde la comunidad local cordillerana se pasa a espacios urbanos, desde donde se vuelve a politizar lo rural andino y los recursos. El territorio de estas identidades en eclosión adquiere un carácter multiescalar al pasar desde espacios familiares a cuencas completas, demandándole a las políticas indígenas nacionales y mundiales, el reconocimiento y protección de sus territorios.

\section{Conclusión}

En este artículo se ha sostenido que la identidad étnica y el territorio son procesos sociales que no son naturales, pero tampoco son simplemente creados, inventados o impuestos (Li, 2000). Por el contrario, emergen de una articulación de diferentes elementos que operan muchas veces de manera contradictoria, y que terminan por producir que ciertas poblaciones reivindiquen etnicidades y que sobrepasen el territorio que históricamente se les había asignado. El caso de los aymaras en el Norte Grande ilustra como las poblaciones que persisten en el altiplano y la precordillera han logrado, en alianza con la población que viven en las ciudades, levantar demandas sociales, culturales, ambientales y territorialidades, en dinámicas de negociación y conflicto con instituciones gubernamentales y con empresas mineras, que estabiliza ciertos etno-territorios como aymaras. Las transformaciones actuales, desde la lectura de la postcomunalidad y de la política neoliberal multicultural, han generado una nueva geografía aymara: por una parte, han aumentado el número de comunidades y asociaciones indígenas que conectan el territorio originario del altiplano y la precordillera, con la población indígena que vive en zonas urbanas, como Arica, Iquique y Alto Hospicio. Por otra parte, se reconoce a las comunidades como organizaciones que tienen presencia territorial, y que demandan el control de la tierra y el agua, fuertemente presionada por el crecimiento urbano y el boom minero. Al mismo tiempo, se crean las ADIs como forma de reconocer un territorio para la población indígena, donde se focalizan recursos para mejorar la calidad de vida de las comunidades y la sustentabilidad del territorio, a través de proyectos de etno-desarrollo. En los sectores urbanos, aumenta de manera progresiva el número de personas que se auto-identifica como aymara, al mismo tiempo que aumenta la certificación de aymaras en los registros de CONADI. Es decir, se crea un "nexo recursivo entre agentes indígenas que se etnifican y agencias públicas que construyen la política en relación con agentes etnificados" (Gundermann et al., 2014: 397), que ve generando la consolidación de una conciencia étnica como pueblo aymara. Una mayor atención a estos temas contribuiría a ver las relaciones entre los pueblos indígenas, el estado y las empresas mineras como relaciones conflictivas, pero altamente productivas, a la vez que contribuiría a avanzar hacia una necesaria des-esencialización de los discursos sobre las identidades y territorios 


\section{Referencias bibliográficas}

AMILHAT SZARY, A. Cultura de Fronteras. En: NATES, B. (editora). Frontera, Fronteras. Manizales: Editorial Universitaria de Caldas, 2013, p. 43-60.

ANDERSON, B. Imagined communities: reflections on the origin and spread of nationalism. London: Verso, 1983.

ANDERSON, M. When Afro becomes (like) indigenous: Garifuna and Afro Indigenous Politics in Honduras. The Journal of Latin American and Caribbean Anthropology, 2007, Vol. 12, № 2, p. 384413.

ARANDA, C. y GELY, M. Aymaras sin fronteras, prácticas paradiplomáticas al servicio de la (re) territorialización identitaria. En: GONZÁLEZ, S., OVANDO, C. y BRETÓN, I. (editores). Del hito a la apacheta. Bolivia-Chile: otra lectura de cien años de historia transfronteriza (1904-2004). Santiago de Chile: RIL Editores, 2016, p. 97-112.

ARAVENA, A. Identidad indígena en Chile en contexto de migración, urbanización y globalización. Amérique Latine Histoire et Mémoire. Les Cahiers ALHIM, 2014, № 27. Disponible en Internet: http://alhim.revues.org/4942

BARABAS, A. Etnoterritorios y rituales terapéuticos en Oaxaca. Scripta Ethnologica, 2002, № 24, p. 9-19.

BARABAS, A. Cosmovisiones y etnoterritorialidad en las culturas indígenas de Oaxaca. Antípoda. Revista de Antropología y Arqueología, 2008, № 7, p. 119-139.

BARTH, F. (compilador). Los grupos étnicos y sus fronteras. Ciudad de México: Fondo de Cultura Económica, 1976.

BATES, R. Unions, parties and political development. A study of mineworkers in Zambia. New Haven: Yale University Press, 1971.

BELLO, A. La acción colectiva de los pueblos indígenas. etnicidad y ciudadanía en América Latina. Santiago de Chile: Comisión Económica para América Latina y el Caribe (CEPAL), 2004.

BELLO, A. ¿Pertenencia o identidad? Implicancias de dos categorías socioculturales para los derechos indígenas y la lucha contra el racismo. Revista Antropologías del Sur, 2016, № 6, p. 13-27.

BENGOA, J.; CANIGUAN, N.; DURÁN, D.; ALLENDE, M.; GERVAIN, M.; VILLARROEL, F. y GAJARDO, P. Mapuche. Procesos, políticas y culturas en el Chile del Bicentenario. Santiago de Chile: Catalonia, 2012.

BRIONES, C. La aboriginalidad como forma de organizar las diferencias. La alteridad del cuarto mundo. Una descronstrución antropológica de la diferencia. Buenos Aires: Ediciones del Sol, 1998. 
BROWMAN, D. Tiwanaku expansion and altiplano economic patterns. Estudios Arqueológicos, 1980, No 5, p. 107-120.

BRYAN, J. Rethinking territory: social justice and neoliberalism in Latin America's territorial turn. Geography Compass, 2012, Vol. 6, N 4, p. 215-226.

CARRASCO, A. y FERNÁNDEZ, E. Estrategias de Resistencia Indígena frente al Desarrollo Minero. La Comunidad de Likantatay ante un posible traslado forzoso. Estudios Atacameños, 2009, № 38 , p. 75-92.

CARRASCO, A. y GONZÁLEZ, H. Movilidad poblacional y procesos de articulación rural-urbano entre los aymara del norte de Chile. Si Somos Americanos, 2014, Vol. 14, № 2, p. 217-231.

CASTREE, N. Differential geographies: place, indigenous rights and 'local' resources. Political geography, 2004, Vol. 23, N² 2, p. 133-167.

CASTRO, L. Cariquimas, islugas y llicas: la frontera chileno-boliviana de Tarapacá y las disputas interétnicas por los recursos productivos de altura, 1883-1931. En: GONZÁLEZ, S., OVANDO, C. y BRETÓN, I. (editores). Del hito a la apacheta. Bolivia-Chile: otra lectura de cien años de historia transfronteriza (1904-2004). Santiago de Chile: RIL Editores, 2016, p. 113-143.

CASTRO, M. Agua, Derechos y Cultura en los Andes del Norte de Chile: Un Enfoque desde la Antropología Jurídica. Chungará: Revista de Antropología, 1997, Vol. 29, №1, p. 63-80.

CASTRO, M. y BAHAMONDES, M. Cambios en la Tenencia de la Tierra en un Pueblo de la PrecordiIlera del Norte de Chile: Socoroma. Revista Chilena de Antropología, 1987, N 6, p. 35-57.

CHAMORRO, A. Carnaval Andino en la ciudad de Arica: Performance en la frontera norte chilena. Estudios Atacameños, 2013, № 45, p. 41-54.

CONADI. Plan director Área de Desarrollo Indígena Jiwasa Oraje. Iquique: CONADI, 2011.

COOMBES, B.; JOHNSON, J. \& HOWITT, R. Indigenous geographies I: Mere resource conflicts? The complexities in Indigenous land and environmental claims. Progress in Human Geography, 2012, Vol. 36, $N^{\circ} 6$, p. $810-821$

DE LA CADENA, M. y STARN, O. Indigeneidad: problemáticas, experiencias y agendas en el nuevo milenio. Tabula Rasa, №10, p. 191-224.

FOUCAULT, M. Arqueología del Saber. Madrid: Siglo XXI, 1979.

GARCÍA, M. Making indigenous citizens: identities, education, and multicultural development in Peru. Stanford University Press, 2005.

GAVILÁN, V. Ser indio y ciudadano en el norte chileno: Etnicidad y estatus de pertenencia a la comunidad nacional y política. Revista de Geografía Norte Grande, 2015, Nº60, p. 63-77. 
GAVILÁN, V. y LAGOS, F. ¿Integración social y subordinación política de los aymara?: un estudio de la certificación estatal indígena en el norte chileno. Estudios Atacameños, 2014, № 49, p. 95-110.

GEERTZ, C. The interpretation of cultures. New York: Basic books, 1973.

GLAZER, N. y MOYNIHAN, D. (editores). Ethnicity: Theory and experience. Cambridge: Harvard University Press, 1975.

GONZÁLEZ, H.; GUNDERMANN, H. y HIDALGO, J. Comunidad indígena y construcción histórica del espacio entre los aymara del Norte de Chile. Chungará, 2014, Vol. 46, N² 2, p. 233-246.

GONZÁLEZ, H. y GUNDERMANN, H. Acceso a la propiedad de la tierra, comunidad e identidades colectivas entre los aymaras del norte de Chile (1821-1930). Chungará, 2009, Vol. 41, № 1, p. 51-70.

GONZÁLEZ, S. Las históricas relaciones entre Tarapacá y Oruro: la frustrada tentativa de integración transfronteriza durante ciclo de expansión del salitre (1864-1928). Revista de Geografía Norte Grande, 2011, №50, p. 63-85.

GREBE, M. Procesos Migratorios, Identidad Étnica y Estrategias Adaptativas en las Culturas Indígenas de Chile: Una perspectiva preliminar. Revista Chilena de Antropología, 1998, № 14, p. 55-68.

GUNDERMANN, H. Etnicidad, identidad étnica y ciudadanía en los países andinos y el norte de Chile. Los términos de la discusión y algunas hipótesis de investigación. Estudios Atacameños, 1997, $\mathrm{N}^{\circ} 13$, p. 9-26.

GUNDERMANN, $\mathrm{H}$. Las poblaciones indígenas andinas de Chile y la experiencia de la ciudadanía. En: GUNDERMANN, H.; FOERSTER, R. y VERGARA, I. Mapuches y aymaras. El debate en torno al reconocimiento y los derechos ciudadanos. Santiago de Chile: RIL editores, 2003, p. 19-104.

GUNDERMANN, H. Municipios y pueblos indígenas en Chile. En: ASSIES, W. y GUNDERMANN, H. Movimientos indígenas y gobiernos locales en América Latina. Santiago de Chile: Imprenta Salesianos, 2007, p. 161-198.

GUNDERMANN, H. y GONZÁLEZ, H. Pautas de integración regional, migración, movilidad y redes sociales en los pueblos indígenas de Chile. Universum, 2008, Vol. 23, № 1, p. 82-115.

GUNDERMANN, H.; GONZÁLEZ, H. y DURSTON, J. Relaciones sociales y etnicidad en el espacio aymara chileno. Chungará, 2014, Vol. 46, №3, p. 397-421.

HALE, C. \& MILLAMÁN, R. Cultural agency and political struggle in the era of the indio permitido. Cultural Agency in the Americas, 2006, p. 281-304.

HOSKINS, W. The making of the English landscape. London: Hodder \& Stoughton, 1955.

LARRAÍN, S. y POO, P. (editoras). Conflictos por el agua en Chile: entre los derechos humanos y las reglas del mercado. Santiago de Chile: Programa Chile Sustentable, 2010. 
LEY N 19.253. Diario Oficial de la República de Chile, Santiago de Chile, 05 de octubre de 1993. Disponible en Internet: http://www.leychile.cl/Navegar?idNorma=30620

$\mathrm{LI}, \mathrm{T}$. Articulating indigenous identity in Indonesia: Resource politics and the tribal slot. Comparative studies in society and history, 2000, Vol. 42, №1, p. 149-179.

MAMANI, A. Desecamiento Laguna sector Lagunilla en el territorio ancestral de la comunidad de Cancosa. En: BELLO, A. y AYLWIN, J. (compiladores). Globalización, Derechos Humanos y Pueblos Indígenas. Temuco: Observatorio de Derechos de los Pueblos Indígenas y Alfabeta Impresiones, 2008, p. 392-397.

MARTínEZ, N. Prácticas cotidianas de ancestralización de un territorio indígena: el caso de la comunidad pewenche de Quinquén. Revista de Geografía Norte Grande, 2015, № 62, p. 85-107

MOLINA, F. Competing rationalities in water conflict: Mining and the indigenous community in Chiu Chiu, El Loa Province, northern Chile. Singapore Journal of Tropical Geography, 2012, vol. $33, N^{\circ} 1$, p. 93-107.

MOLINA, R. Reconstrucción de los etno-territorios. En: Tierra, territorio y desarrollo indígena. Temuco: Instituto de Estudios Indígenas, 1995, p. 111-118.

MOLINA, R. Saywaña, amojonamientos y deslindes en Villablanca y Chulluncane: geografía de un conflicto de tierras aimara. Revista de Geografía Norte Grande, 2015, № 62, p. 29-46

MURRA, J. Formaciones económicas y políticas del mundo andino. Lima: IEP Ediciones, 1975.

NIEZEN, R. The Origins Indigenism: human rights and the politics of identity. London: University of California Press, 2002.

NUÑEZ, L. y DILLEHAY. T. Movilidad giratoria, armonía social y desarrollo en los Andes Meridionales: patrones de tráfico e interacción económica. Antofagasta: Dirección General de Investigaciones Científicas y Tecnológicas, Universidad del Norte, 1979.

PARK, R. Human migration and the marginal man. American Journal of Sociology, 1928, Vol. 33, № 6, 881-893.

PASSI, A. Territory. In: AGNEW, J.; MITCHELL, K. \& TOAL, G. A companion to political geography. Oxford: Blackwell, 2003, p. 109-122.

PELUSO N. \& LUND, C. New Frontiers of Land Control: Introduction. The Journal of Peasant Studies, 2011, Vol. 38, N 4, p. 667-681.

PERRAULT, T. Extracting Justice: Natural Gas, Indigenous Mobilization, and the Bolivian State. In: SAWYER, S. \& GOMEZ, T. (editors). The Politics of Resource Extraction: Indigenous Peoples, Multinational Corporations, and the State. London: Palgrave Macmillan, 2012, p. 75-102. 
PERRAULT, T. \& GREEN, B. Reworking the spaces of indigeneity: the Bolivian ayllu and lowland autonomy movements compared. Environment and Planning D: Society and Space, 2013, Vol. 31, No 1, p. 43-60.

POSTERO, N. Introduction: Negotiating Indigeneity. Latin American and Caribbean Ethnic Studies, 2013, Vol. 8, N², p. 107-121.

PRIETO, M. Transando el agua, produciendo territorios e identidades indígenas: el modelo de aguas chileno y los atacameños de Calama. Revista de Estudios Sociales, 2016, № 55, p. 88-103.

RADCLIFFE, S. Re-mapping the nation: cartography, geographical knowledge and Ecuadorian multiculturalism. Journal of Latin American Studies, 2010, Vol. 42, N² 2, p. 293-323.

RODRÍGUEZ, A. Etnicidad y movimientos sociales: proceso de evaluación del proyecto minero Los Pumas (2010-2015), Norte de Chile. Santiago de Chile: Tesis para el obtener el grado de Master Governance of Risks and Resource, Centro Heidelberg para Latino América, 2016.

ROJAS, J. El hombre que persigue a Cerro Colorado: Luis Jara denuncia que la filial de BHP Billiton extrae agua ilegalmente y usurpa sus territorios. The Clinic, 27 de agosto de 2017. Disponible en Internet: http://www.theclinic.cl/2017/08/27/hombre-persigue-cerro-colorado/

ROMERO-TOLEDO, H. y GUTIÉRREZ, F. Conflictos socioterritoriales mineros: la expansión minera y la articulación identitaria indígena en el Norte Grande de Chile. En: ZHOURI, A., BOLADOS, P. \& CASTRO, E. (editoras). Mineração na America Latina: neoextrativismo e lutas territoriais. Sao Paulo: Annblume, 2016, p. 67-89.

ROSTWOROWSKI, M. Etnia y sociedad: ensayos sobre la costa central prehispánica. Lima: Instituto de Estudios Peruanos, 1977.

SALINAS, J. La comunidad aymara de Cancosa y los acuerdos con la Compañía Minera Cerro Colorado. En: FERNÁNDEZ, M. y SALINAS, J. (compiladores). Defensa de los Derechos Territoriales en Latinoamérica. Santiago de Chile: RIL editores, 2012, p. 211-248.

SCHAEFER, R. (editor). Encyclopedia of race, ethnicity and society. London: SAGE, 2008.

SMITH, A. National identity. London: Penguin Books, 1991.

SMITH, A. The cultural foundations of nations. Hierarchy, covenant, and republic. Oxford: Blackwell Publishing, 2008.

STAVENHAGEN, R. Identidad indígena y multiculturalidad en América Latina. Araucaria, 2002, vol. $4, N^{\circ} 7$, p. 13-22.

THORP, R. \& PAREDES, M. Ethnicity and the persistence of inequality: the case of Peru. London: Palgrave Macmillan, 2010. 
VANDERGEEST, P. \& PELUSO, N. L. Territorialization and state power in Thailand. Theory and Society, 1995, Vol. 24, N³, p. 385-426.

VAN KESSEL, J. La Lucha por el Agua de Tarapacá: la visión andina. Chungará, 1985, № 14, p-.141155.

VAN KESSEL, J. Holocausto al Progreso. Iquique: IECTA, 2003.

VERGARA, J.; GUNDERMANN, H. y FOERSTER, R. Estado, Conflicto étnico y cultura. Estudios sobre pueblos indígenas de Chile. Santiago de Chile: Ocho libros, 2014.

WADE, P. Race and ethnicity in Latin America. London: Pluto press, 2017.

WEBER, M. Ethnic groups. In: HUGHEY, M. (editor). New Tribalisms. Basingstoke: Palgrave MacmiIlan, 1978, p. 17-30.

YAÑEZ, N. y MOLINA, R. La gran minería y los derechos indígenas en el norte de Chile. Santiago de Chile: LOM Ediciones, 2008.

YAÑEZ, N. y MOLINA, R. Las aguas indígenas en Chile. Santiago de Chile: LOM Ediciones, 2011.

ZAPATA, C. Memoria e historia: el proyecto de una identidad colectiva entre los aymarás de Chile. Chungará, 2007, Vol. 39, N², p. 171-183. 